Supporting information for

\title{
Asymmetrically Patterned Cellulose \\ Nanofibers/Graphene Oxide Composite Film \\ for Humidity Sensing and Moist-Induced \\ Electricity Generation
}

Zixiu Li ${ }^{\mathrm{a}}$, Jian Wang ${ }^{\mathrm{a}}$, Lei Dai*a, b, Xuhui Sun ${ }^{\mathrm{c}}$, Meng An*c Chao Duan ${ }^{\mathrm{a}}$, Ji Li*a, Yonghao $\mathrm{Ni}^{* \mathrm{~d}}$

${ }^{\text {a }}$ College of Bioresources Chemical and Materials Engineering, Shaanxi University of Science and Technology, Xi'an, 710021, China.

${ }^{\mathrm{b}}$ College of Chemical and Biological Engineering, Zhejiang University, Hangzhou, 310027, China.

${ }^{c}$ College of Mechanical and Electrical Engineering, Shaanxi University of Science and Technology, Xi'an, 710021, China.

${ }^{\mathrm{d}}$ Department of Chemical Engineering, University of New Brunswick, Fredericton, New Brunswick E3B 5A3, Canada

E-mail addresses: dailei_ju@hotmail.com (L. Dai); anmeng@sust.ed.cn (M. An); liji@sust.edu.cn (J. Li); yonghao@unb.ca (Y. Ni) 


\section{Contents}

Figure S1. TEM images of (a) CNF and (b) GO ............................................. S-1

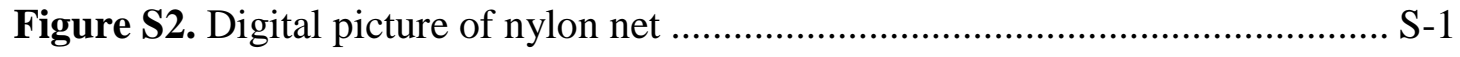

Figure S3. Optical images of $\mathrm{CNF} / \mathrm{GO}$ composite films with different GO contents

Figure S4. Photograph of transmittance of $\mathrm{CNF} / \mathrm{GO}$ composite films with different GO contents under natural light and ultraviolet light S-2

Figure S5. Molecular dynamics simulation of interactions between carbonyl in GO and water

Figure S6. Molecular dynamics simulation of the relationships between deformation rate and $\mathrm{GO}$ content S-2

Figure S7. Water contact angles of CNF/GO films with different GO contents...... S-3

Figure S8. Molecular dynamics simulation of the effect of GO content on the interactions between cellulose and water.

Figure S9. Pictures of deformation ratio of $\mathrm{CNF} / \mathrm{GO}$ composite films with (a) and without (b) patterning at the same relative humidity..... S-4

Figure S10. SEM images of smooth surface and cross section of CNF and CNF/GO films with $7.5 \mathrm{wt} \% \mathrm{GO}$ content S-4

Figure S11. Large area SEM image of the cross-section of CNF/GO films with $7.5 \mathrm{wt} \%$ GO content S-5

Figure S12. SEM picture of cross section of CNF/GO composite film (GO content of $7.5 \mathrm{wt} \%)$ S-5

Figure S13. Finite element analysis of stress distribution of smooth film and asymmetric patterned film under the same stress S-6

Figure S14. Finite element analysis of water transfer rate in patterned channels of different sizes S-6

Figure S15. Photos of (a) finger with gloves and (b) finger without gloves approaching the composite film. 
Table S1. Comparison of the sensing performance of cellulose-based humidity sensors in this work and previous literature S-7

Supplementary video 1. Actuation response of $\mathrm{CNF} / \mathrm{GO}$ composite films driven by

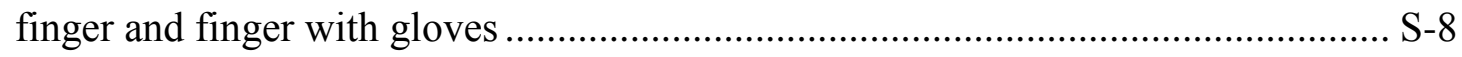

Supplementary video 2. Stimulus response behavior of CNF/GO Mimosa........... S-8 Supplementary video 3. Power generation process of CNF/GO-based

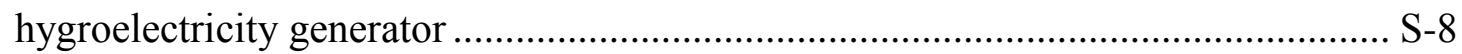

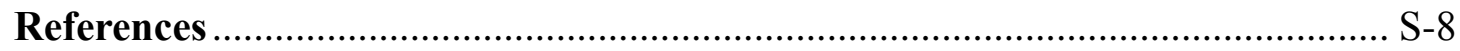




\section{Supplementary figures and table}

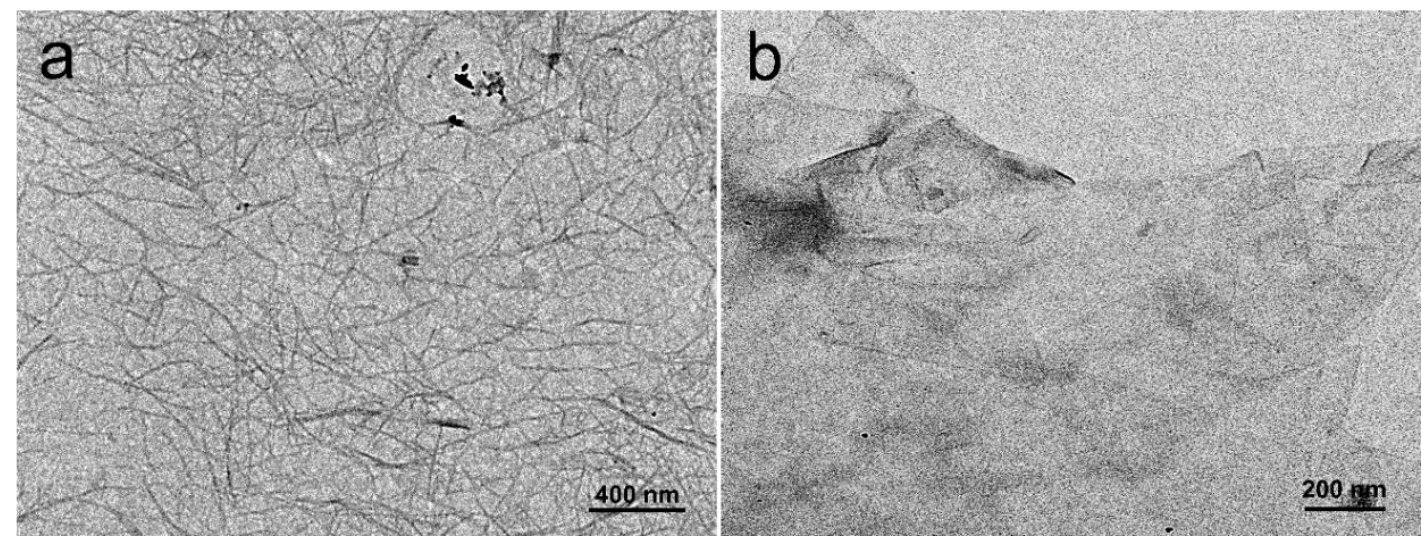

Figure S1. TEM images of (a) CNF and (b) GO.

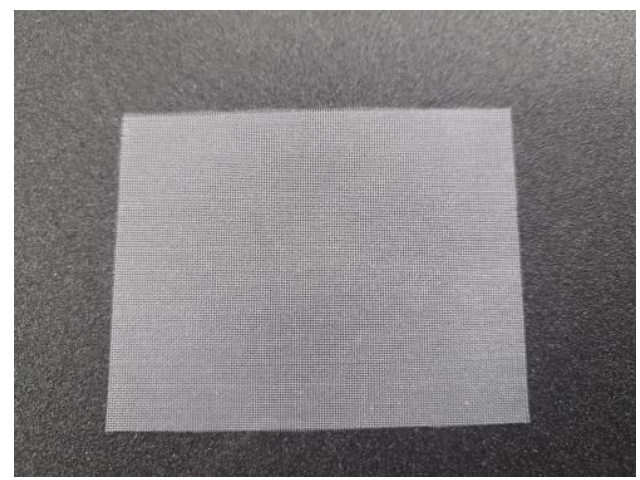

Figure S2. Digital picture of nylon net.
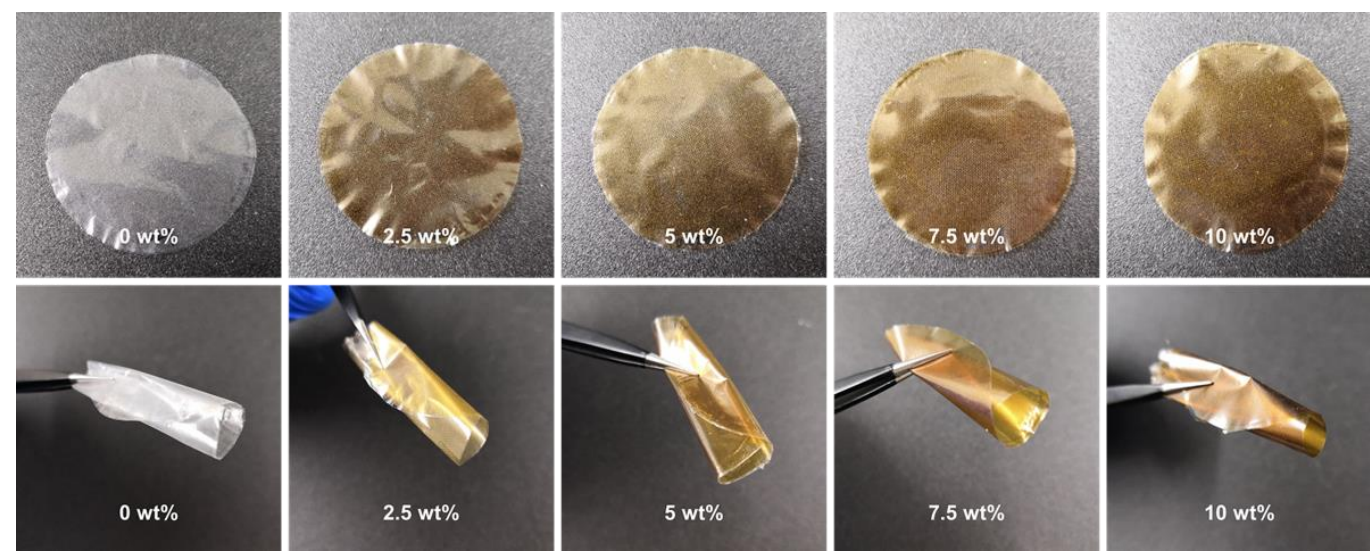

Figure S3. Optical images of CNF/GO composite films with different GO contents. 


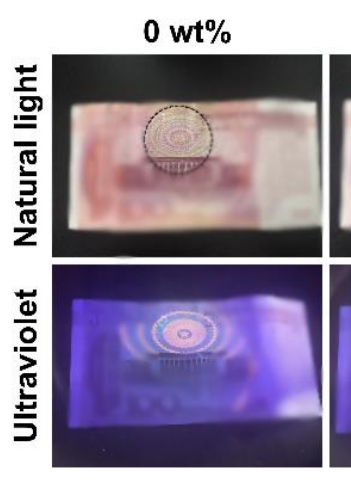

$2.5 w t \%$

$5.0 \mathrm{wt} \%$

$7.5 w t \%$

$10.0 w t \%$
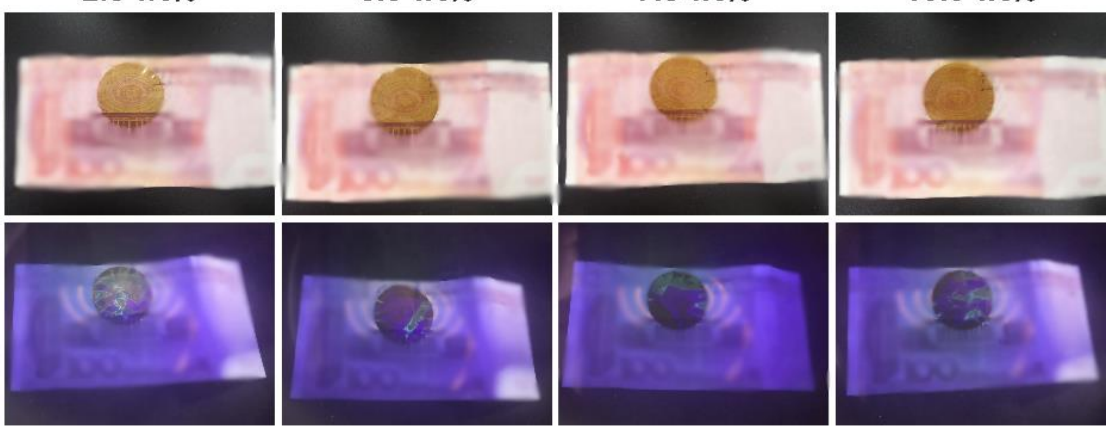

Figure S4. Photograph of transmittance of $\mathrm{CNF} / \mathrm{GO}$ composite films with different GO contents under natural light and ultraviolet light.

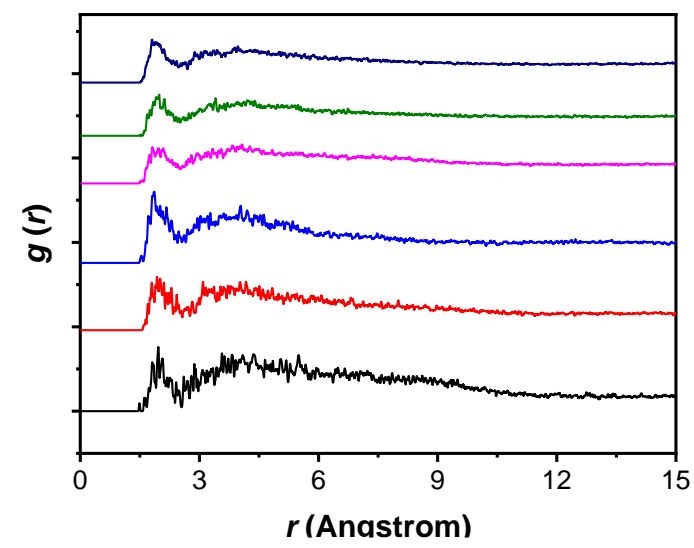

Figure S5. Molecular dynamics simulation of interactions between carbonyl in GO and water.

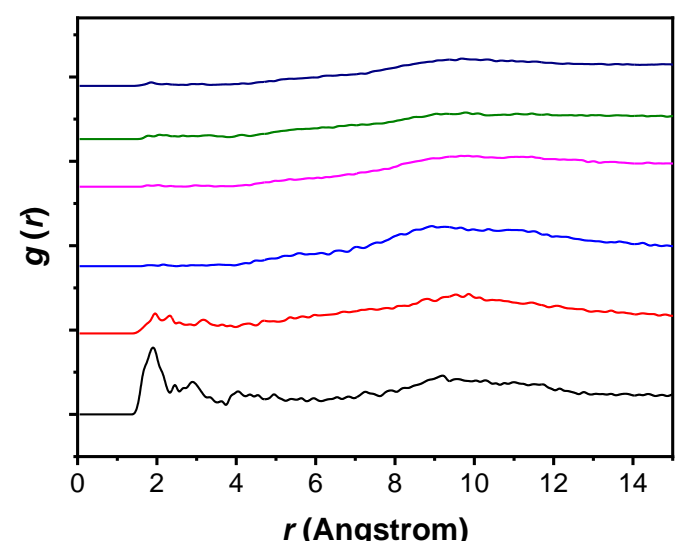

Figure S6. Molecular dynamics simulation of the relationships between deformation rate and $\mathrm{GO}$ content. 


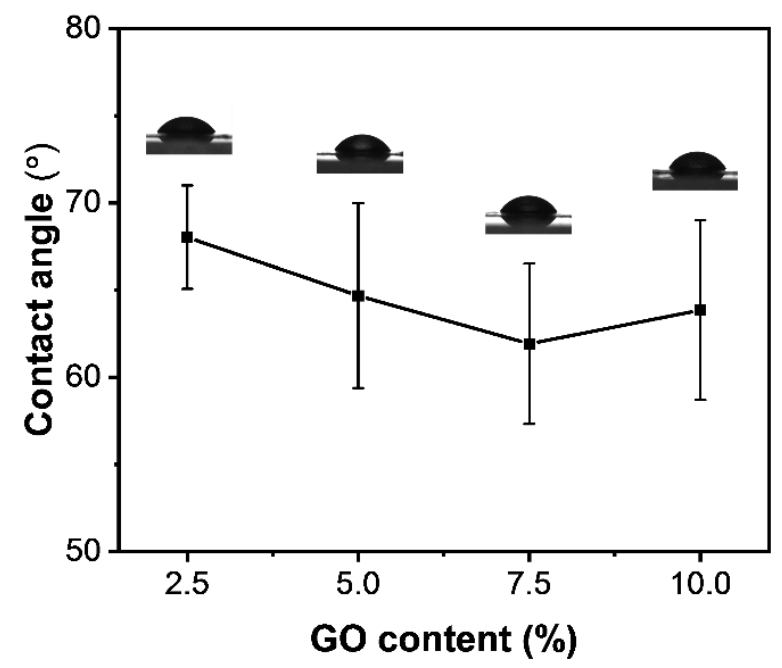

Figure S7. Water contact angles of CNF/GO films with different GO contents.

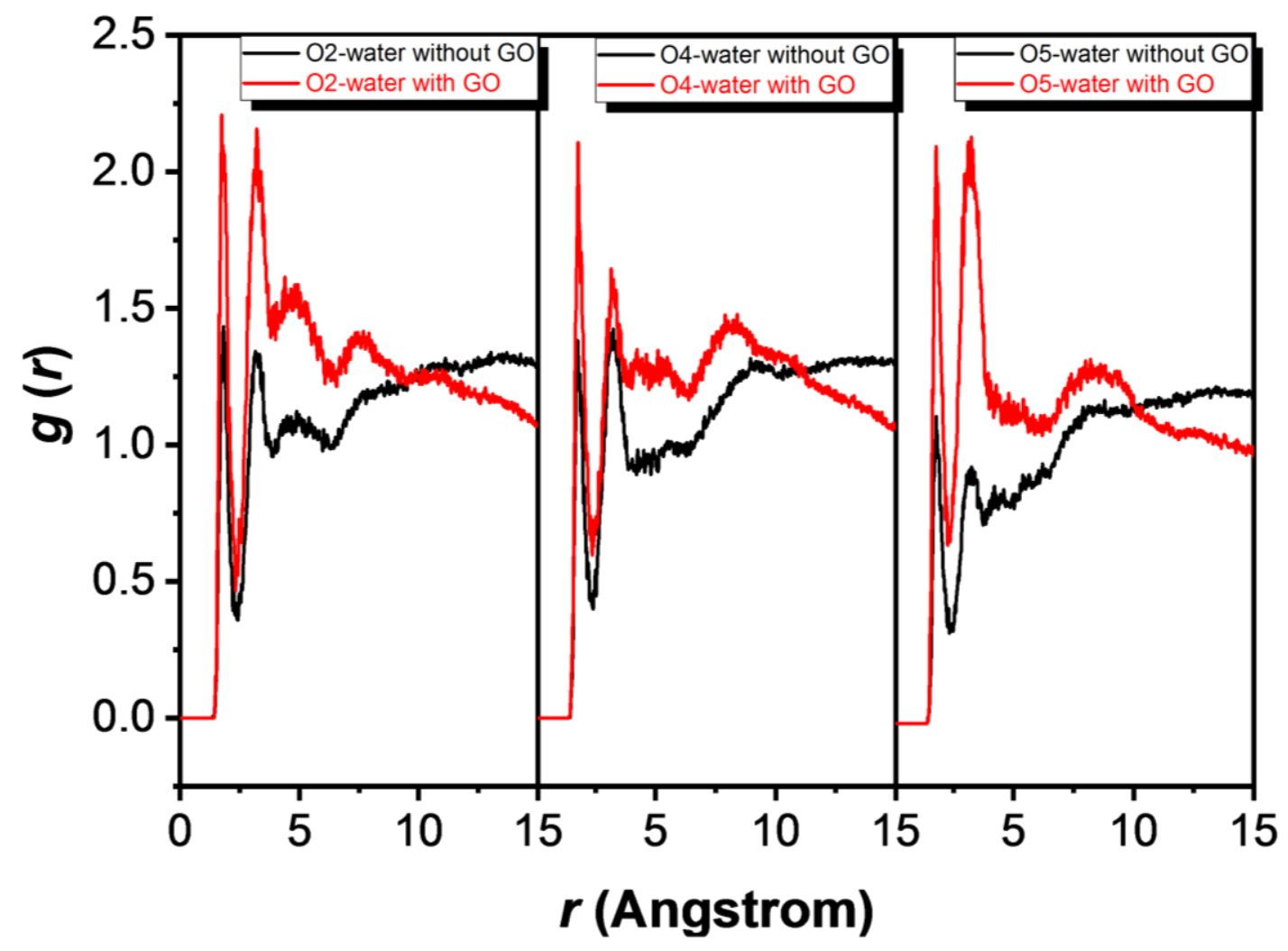

Figure S8. Molecular dynamics simulation of the effect of GO content on the interactions between cellulose and water. 


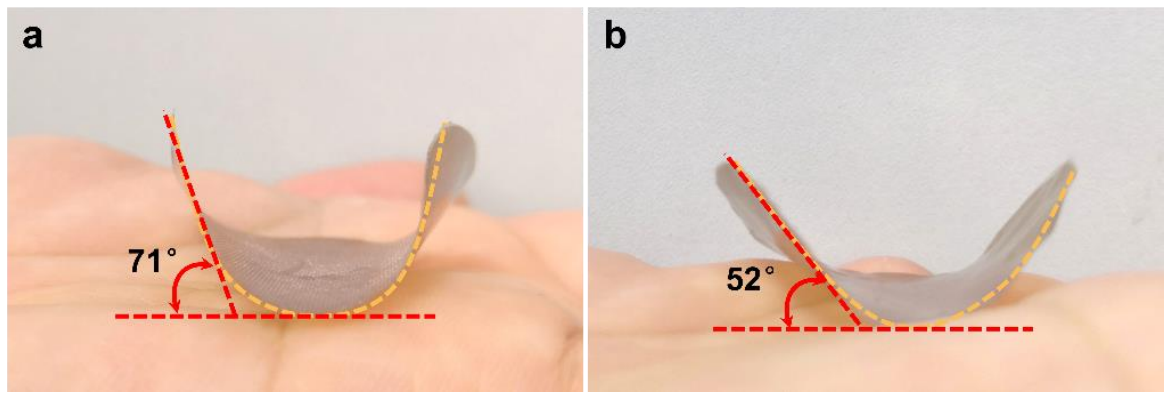

Figure S9. Pictures of deformation ratio of $\mathrm{CNF} / \mathrm{GO}$ composite films with (a) and without (b) patterning at the same relative humidity.

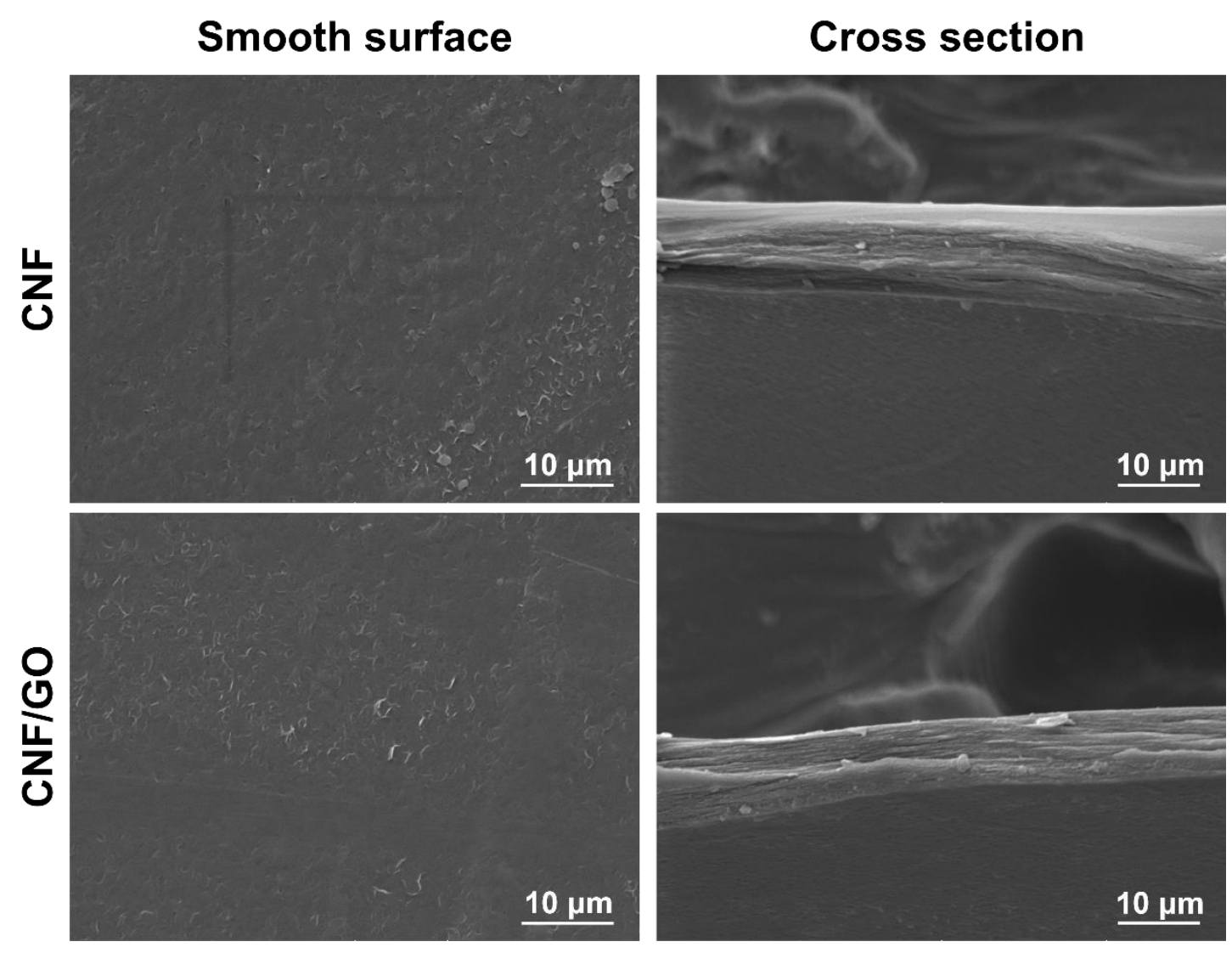

Figure S10. SEM images of smooth surface and cross section of CNF and CNF/GO films with $7.5 \mathrm{wt} \%$ GO content. 


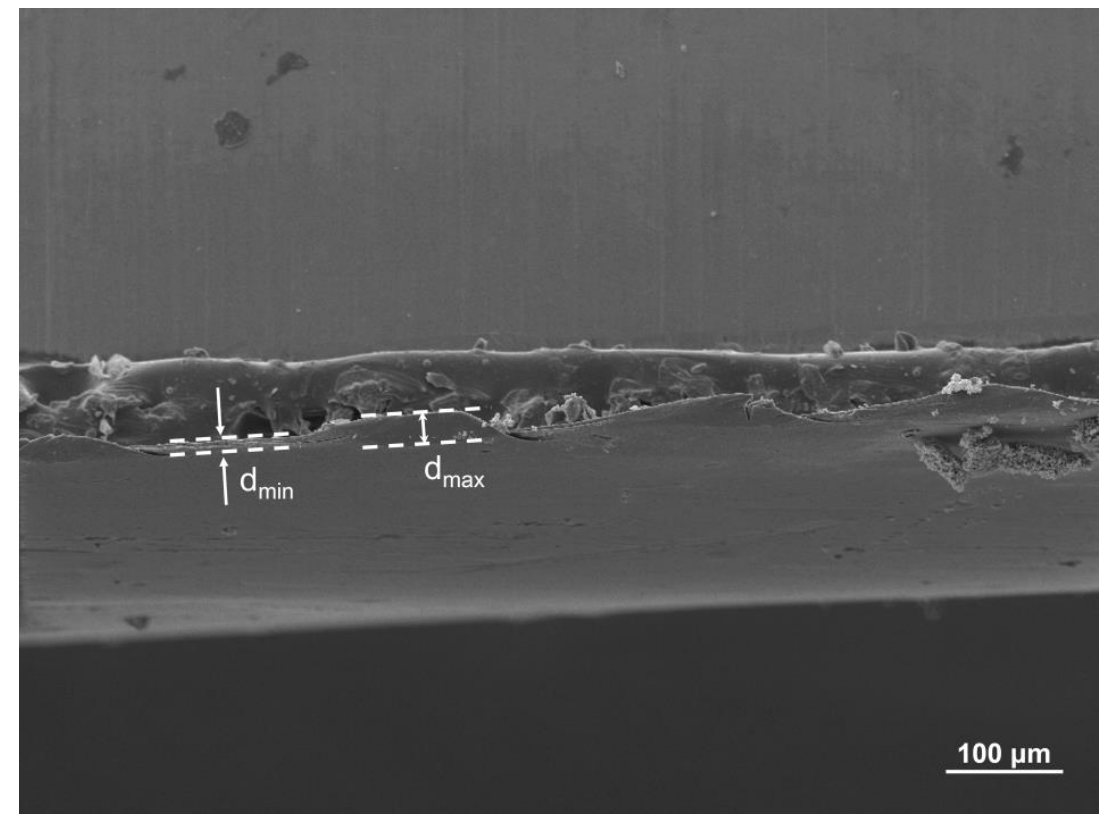

Figure S11. Large area SEM image of the cross-section of CNF/GO films with $7.5 \mathrm{wt} \%$ GO content.

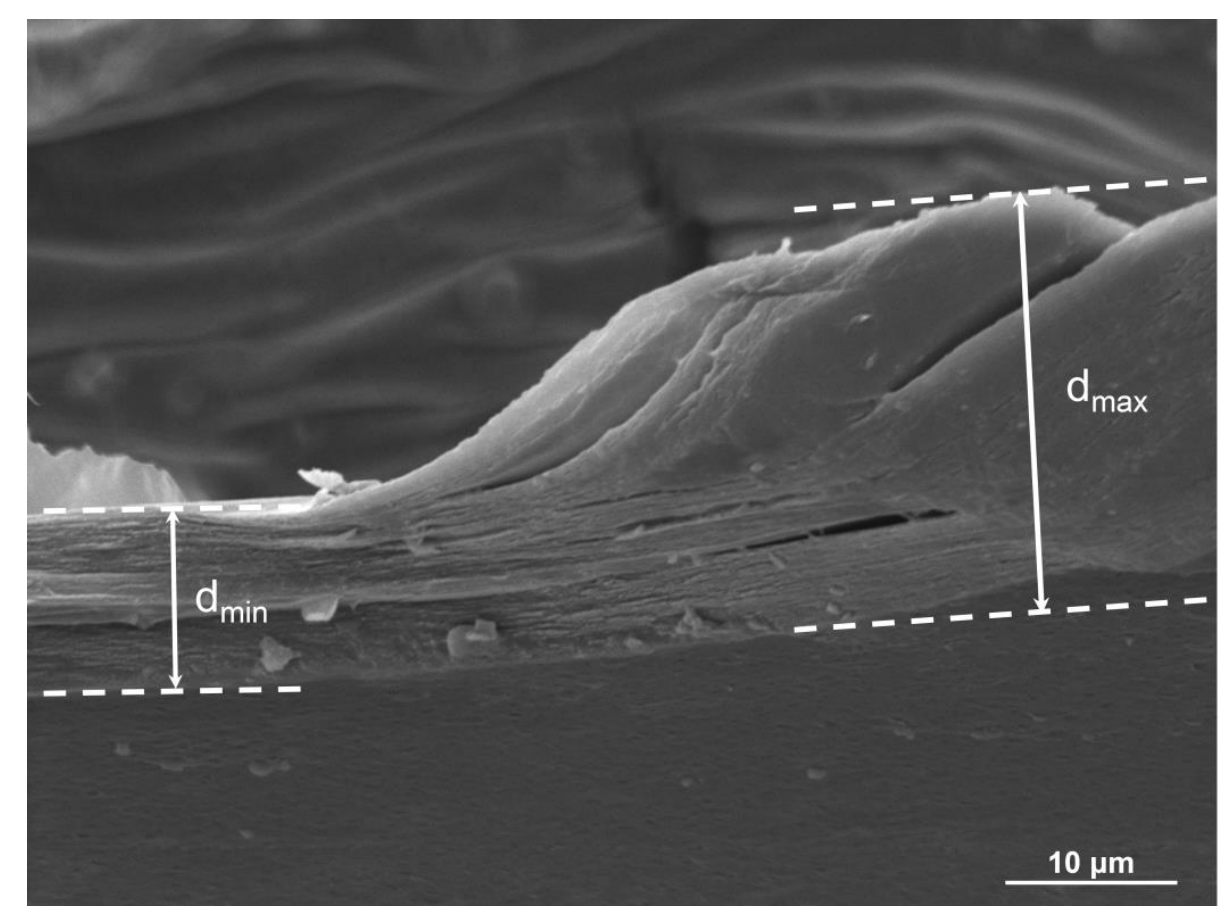

Figure S12. SEM picture of cross section of CNF/GO composite film (GO content of $7.5 \mathrm{wt} \%)$. 


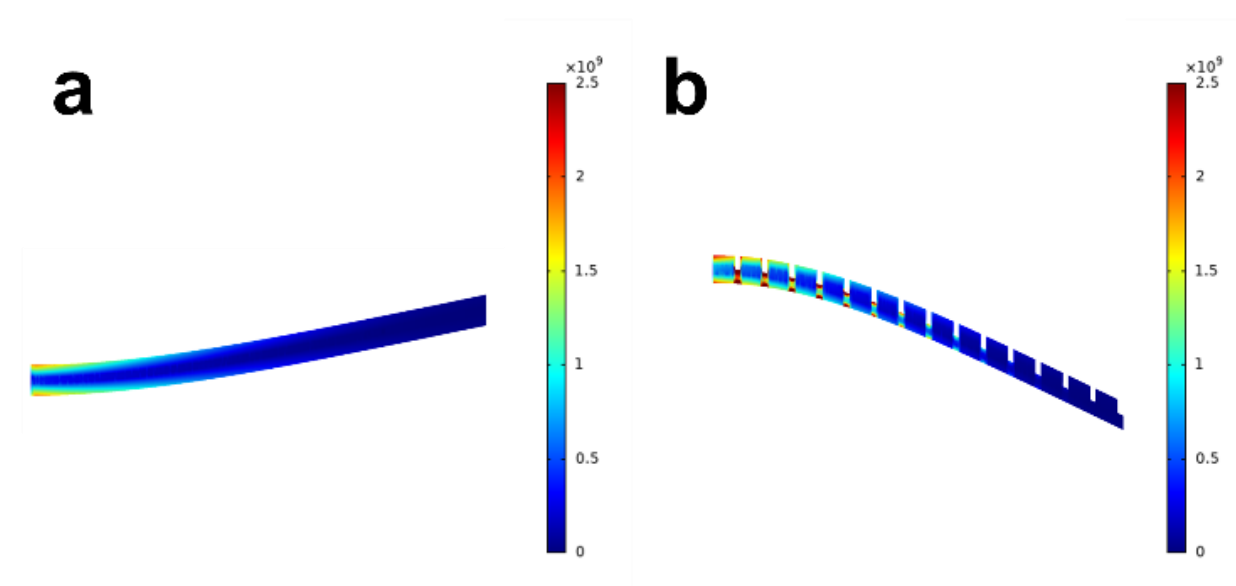

Figure S13. Finite element analysis of stress distribution of smooth film and asymmetric patterned film under the same stress.

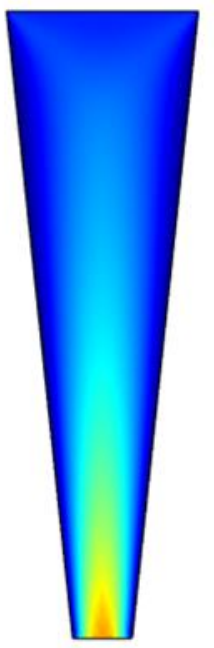

a

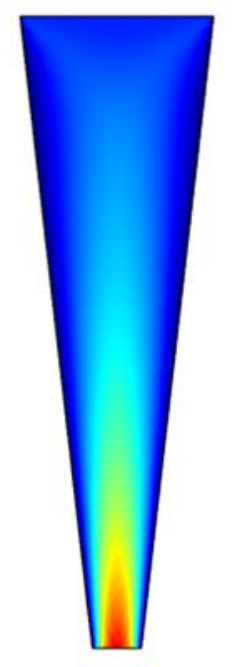

b

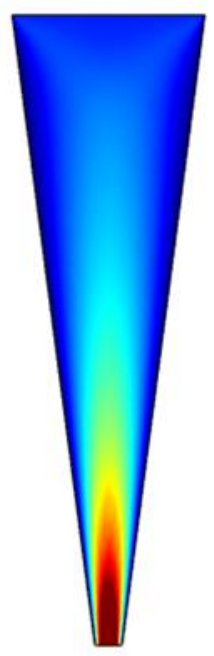

C

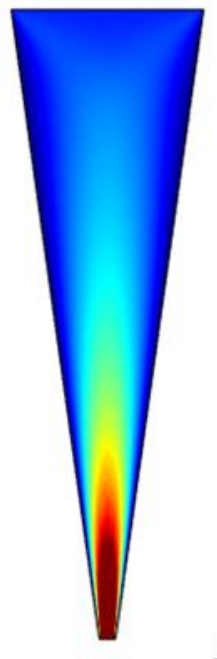

d
0.16

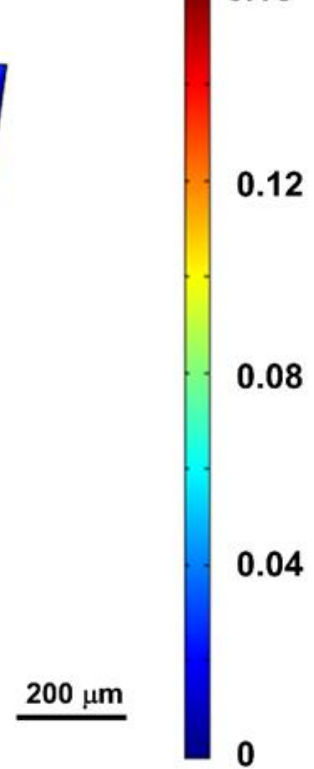

0.04

Figure S14. Finite element analysis of water transfer rate in patterned channels of different sizes. The size of the inlet is $354.8 \mu \mathrm{m}$. The outlet sizes are (a) $100 \mu \mathrm{m}$, (b) $90 \mu \mathrm{m}$, (c) $50 \mu \mathrm{m}$ and (d) $30 \mu \mathrm{m}$, respectively. 

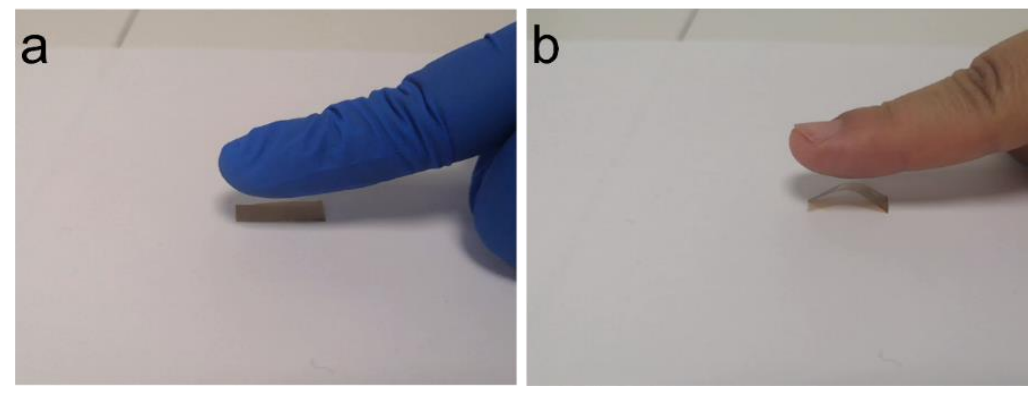

Figure S15. Photos of (a) finger with gloves and (b) finger without gloves approaching the composite film.

Table S1. Comparison of the sensing performance of cellulose-based humidity sensors in this work and previous literature.

\begin{tabular}{|c|c|c|c|c|c|}
\hline No. & Material & Mechanism & RH range & $\begin{array}{c}\text { Response } \\
\text { time }\end{array}$ & Refs \\
\hline 1 & $\begin{array}{c}\text { Cellulose acetate-copper } \\
\text { oxide }\end{array}$ & $\begin{array}{l}\text { Resistance } \\
\text { and } \\
\text { capacitance }\end{array}$ & $0-90 \%$ & $13 \mathrm{~s}$ & $1 *$ \\
\hline 2 & $\begin{array}{l}\text { Carbon nanotube coated } \\
\text { cellulose paper }\end{array}$ & Resistance & $10-75 \%$ & $6 s$ & $2 *$ \\
\hline 3 & Cellulose nanocrystals & QCM & $11.3-97.3 \%$ & $31-60 s$ & 23 \\
\hline 4 & $\begin{array}{l}\text { Oxidized multiwalled } \\
\text { carbon nanotubes inks } \\
\text { coating on paper }\end{array}$ & Resistance & $33-95 \%$ & $470 \mathrm{~s}$ & $3 *$ \\
\hline 5 & Cellulose-polypyrrole & Capacitance & $30-90 \%$ & $\sim 418 \mathrm{~s}$ & $4 *$ \\
\hline 6 & Bacterial cellulose & QCM & $20-97 \%$ & $89-119 \mathrm{~s}$ & $5 *$ \\
\hline 7 & $\begin{array}{l}\text { Nanofibrillated } \\
\text { cellulose/MWCNTs } \\
\text { composite film }\end{array}$ & Resistance & $11-95 \%$ & $330 \mathrm{~s}$ & $6 *$ \\
\hline 8 & $\begin{array}{l}\text { Polyaniline-carboxymethyl } \\
\text { cellulose }\end{array}$ & Resistance & $25-75 \%$ & $10 \mathrm{~s}$ & $7 *$ \\
\hline 9 & Cellulose/KOH & Resistance & $11.3-97.3 \%$ & $6 \mathrm{~s}$ & 28 \\
\hline 10 & $\mathrm{CNF} / \mathrm{GO}$ & $\begin{array}{c}\text { Shape } \\
\text { deformation }\end{array}$ & $25.0-85.4 \%$ & $3-5 \mathrm{~s}$ & $\begin{array}{l}\text { This } \\
\text { work }\end{array}$ \\
\hline
\end{tabular}


Supplementary video 1 . Actuation response of $\mathrm{CNF} / \mathrm{GO}$ composite films driven by finger and finger with gloves.

Supplementary video 2. Stimulus response behavior of CNF/GO Mimosa. Supplementary video 3. Power generation process of CNF/GO-based hygroelectricity generator.

\section{REFERENCES}

(1*) Chani, M. T. S.; Karimov, K. S.; Khan, S. B.; Asiri, A. M. Fabrication and Investigation of Cellulose Acetate-Copper Oxide Nano-Composite Based Humidity Sensors. Sensor Actuat A: Phys 2016, 246, 58-65.

(2*) Han, J. W.; Kim, B.; Li, J.; Meyyappan, M. Carbon Nanotube Based Humidity Sensor on Cellulose Paper. J. Phys. Chem. C 2012, 116, 22094-22097.

(3*) Zhao, H.; Zhang, T.; Qi, R.; Dai, J.; Liu, S.; Fei, T. Drawn on Paper: A Reproducible Humidity Sensitive Device by Handwriting. ACS Appl. Mater. Interf 2017, 9, 28002-28009.

(4*) Mahadeva, S. K.; Yun, S.; Kim, J. Flexible humidity and temperature sensor based on cellulose-polypyrrole nanocomposite. Sensor Actuat A: Phys 2011, 165, 194-199.

(5*) Hu, W.; Chen, S.; Zhou, B.; Liu, L.; Ding, B.; Wang, H. Highly Stable and Sensitive Humidity Sensors Based on Quartz Crystal Microbalance Coated with Bacterial Cellulose Membrane. Sensor Actuat B: Chem 2011, 159, 301-306.

(6*) Zhu, P.; Liu, Y.; Fang, Z.; Kuang, Y.; Zhang, Y.; Peng, C.; Chen, G. Flexible and Highly Sensitive Humidity Sensor Based on Cellulose Nanofibers and Carbon Nanotube Composite Film. Langmuir 2019, 35, 4834-4842. 
(7*) Kotresh, S.; Ravikiran, Y. T.; Raj Prakash, H. G.; Ramana, C. V. V.; Vijayakumari, S. C.; Thomas, S. Humidity Sensing Performance of Spin Coated Polyaniline-Carboxymethyl Cellulose Composite at Room Temperature. Cellulose 2016, 23, 3177-3186. 